\title{
PHOTOGRAPHIC RECORDING OF NATURAL ACTIVITY IN HIBERNATING BATS')
}

by

\author{
SERGE DAAN \\ Dierfysiologisch Laboratorium, Universiteit van Amsterdam, The Nederlands
}

In the past decade there has been an increasing awareness that spontaneous activity in hibernating mammals is not a mere accidental imperfection in the mechanism of hibernation but, on the contrary, a regular and important feature of it. Several recent investigations (e.g. Kristofferson \& Soivio, 1967; Pohl, 1967) have dealt with activity of mammals hibernating under laboratory conditions. Comparatively little is known of activity patterns during the hibernation season in natural circumstances. In the framework of studies on the ecological factors involved in activity during hibernation field investigations were made in several winter quarters of bats.

In these investigations, a complete account of which is to be published elsewhere, two methods have been used to measure rates of activity in the populations. One is the constant interval search with calculation of the relative number of bats which have moved from their locations each interval (Daan, in press). The other method involves photographing active bats as they fly through a

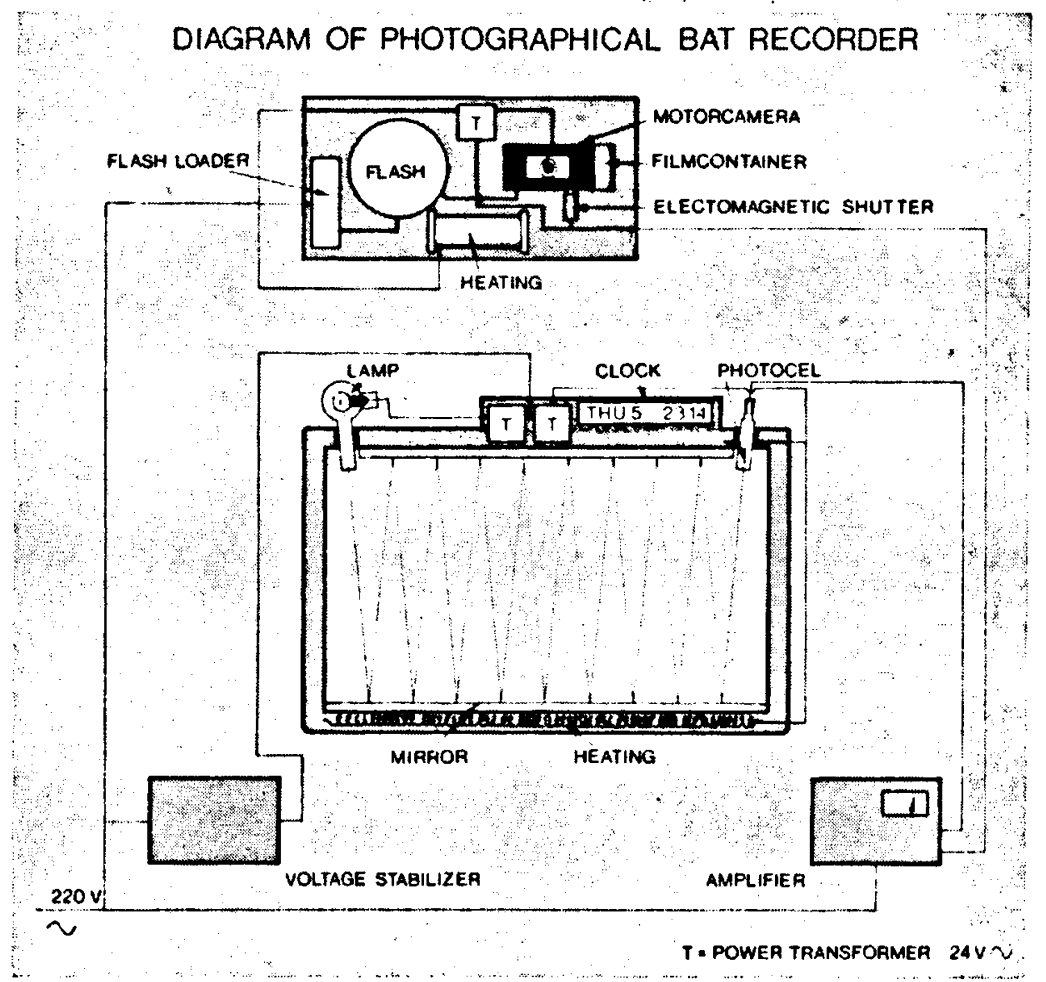

Fig. 1. Diagram of photographic bat recorder.

1) Supported by research grant $945-25$ from the Netherlands' Organization of Pure Research (ZWO). 
passage in the hibernaculum. A photocamera was used in preference to any other form of recording in order to be able to distinguish between species and even between individuals. The equipment developed will be described in the present paper and illustrated with a few preliminary results.

\section{APPARATUS}

In recording activity in summer colonies of bats (e.g., Nyholm, 1965; Engländer \& Laufens, 1968) the detector is usually a photocell illuminated by a simple light beam - or a direction discriminating double system (Böhme \& Natuschke, 1967) through a narrow pathway of the colony. In the artificial limestone quarry currently being investigated I had the problem of far larger passages, in the order of $10 \mathrm{~m}^{2}$ in cross section, which could not be reduced to a mere slit without strongly affecting bat behaviour as well as cave climate. The intermediate solution found was to reduce the passage by wire netting to a window of $0.75 \times 1 \mathrm{~m}^{2}$. This window (fig. 1) is an iron frame containing two parallel mirrors $(935 \times 10 \times 2 \mathrm{~mm})$ at top and bottom. A light source (Osram 8017, $6 \mathrm{~V}$, $15 \mathrm{~W}$ ) is in the upper left, emitting through a red filter a parallel light beam, which is reflected fifteen times by the mirrors and is then condensed by a lens in front of a sensitive photodiode (Philips 58CG). An interruption of the beam anywhere in the window by an animal as large as our smallest species of bat obscures the photocell. This signal is fed into an amplifier ${ }^{2}$ ) which triggers the electromagnetic shutter of an automatic camera.

The camera (Robot Motor Recorder $36 \mathrm{M}$ maximum frequency 2 frames per second - with container for 10 meters $36 \mathrm{~mm}$ film, and Schneider-Xenar $1: 2,8 / 45 \mathrm{~mm}$ lens) is mounted in an iron case $(57 \times 27 \times 26 \mathrm{~cm})$, hanging from the ceiling and directed obliquely down towards the window (distance about $160 \mathrm{~cm}$ ). In the case are also a $24 \mathrm{~V}$ D.C. power transformer and an electronic flash with flash loader (Mannesmann Multiblitz Filius II; flash duration $1.2 \mathrm{msec}$; interval 2-6 sec.). The photograph taken will show a picture of the window with the bat passing through. Date and the time shown on the clock are likewise recorded.

As the air in the quarry is nearly saturated with water, the risk of condensation on both parts of the

2) The design and construction of the electronic part of the apparatus by Mr. H. Bakema is gratefully acknowledged.

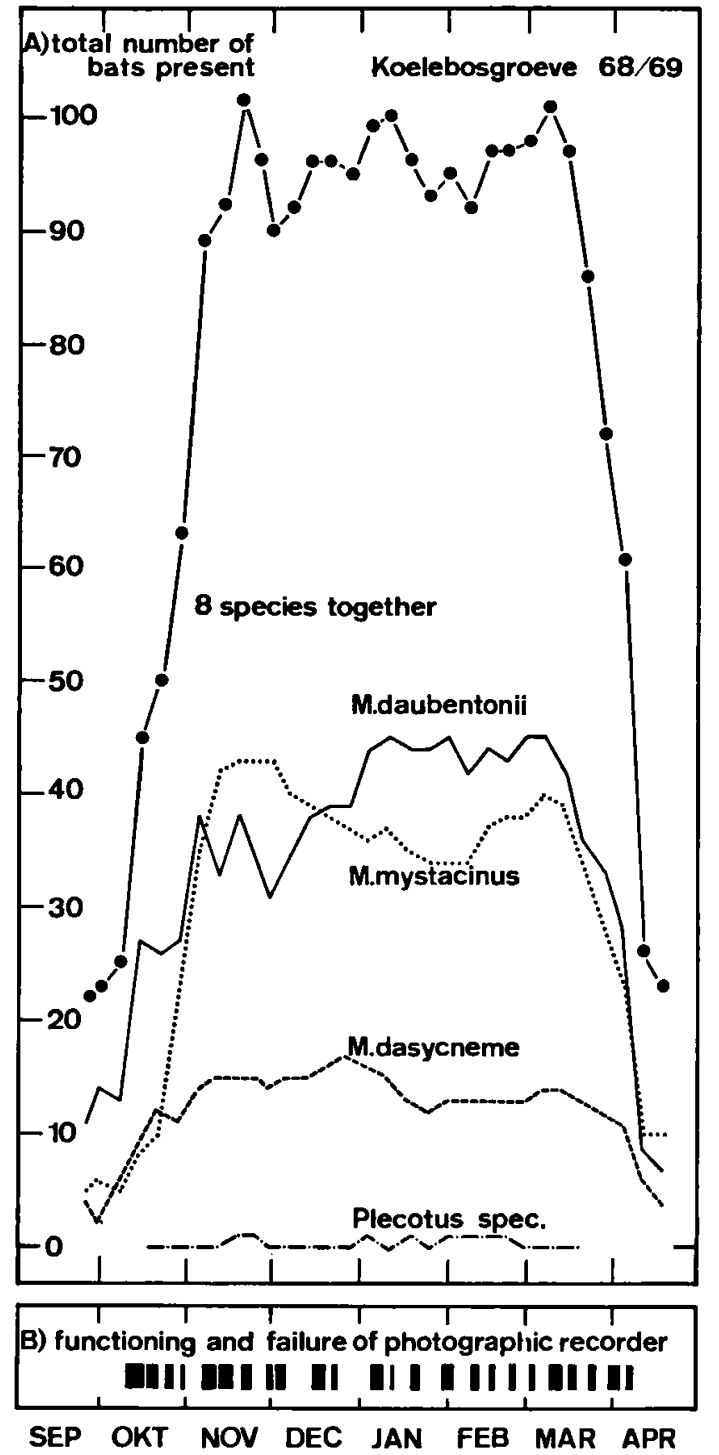

Fig. 2. Number of bats counted in the quarry (A) and functioning of the recorder (B).

set-up had to be avoided. This was accomplished by mounting a heating wire directly underneath the mirrors as well as in the camera and flash case. These were thereby kept at a sufficient temperature difference of 1 to $2^{\circ} \mathrm{C}$ above the ambient. A voltage stabilizer was necessary to reduce fluctuations in the light intensity of the lamp and to compensate for voltage loss in the $500 \mathrm{~m}$ cable to the nearest mains in a farmhouse.

The photographic recorder was first set up in the winter of $1968 / 69$ close behind the gate in the entrance of the "Koelebosgroeve", a $8300 \mathrm{~m}^{2}$ surface subterranean limestone quarry in the municipality of Bemelen (South Limburg). The bats 
Distribution of recorded flights from the cave.

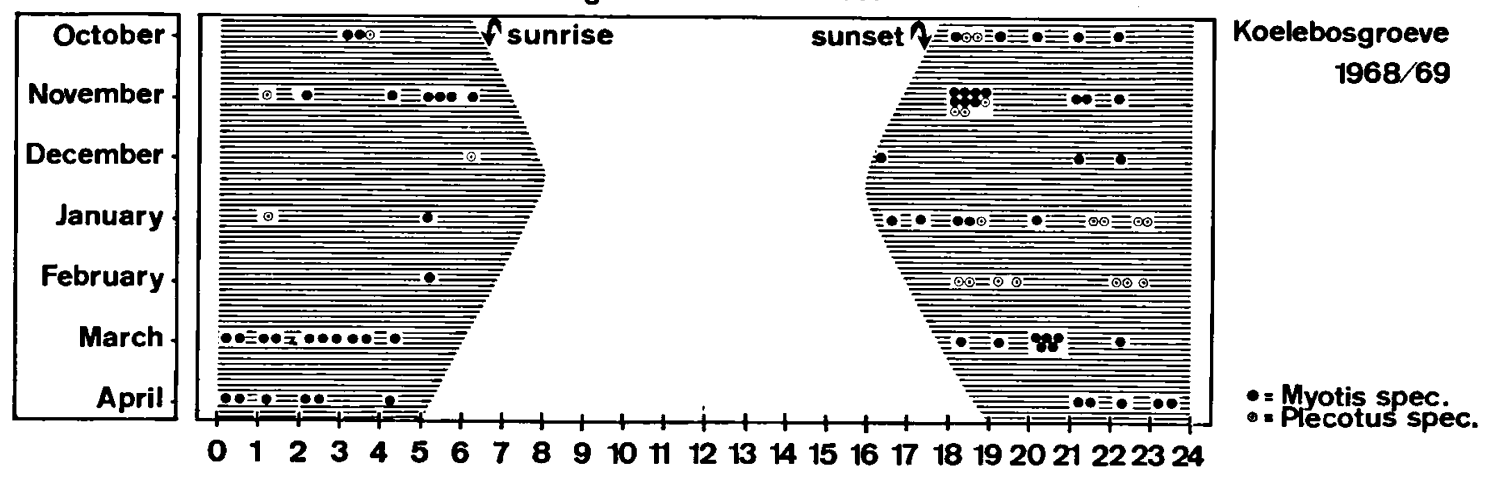

Fig. 3. Distribution of recorded exit flights over 24 hours.

hibernating in this quarry were of eight species: Myotis daubentonii (44\%), M. mystacinus (38 $\%), M$. dasycneme $(15 \%$ and incidental specimens of Myotis myotis, $M$. emarginatus, $M$. nattereri, Eptesicus serotinus, and Plecotus spec. (Percentages are averaged over December, January, and February). Their populations were counted during 31 weekly searches in the quarry from September 21, 1968 to April 18, 1969 (fig. 2A). Nearly all bats were marked with plastic head markings (Daan, in press) when found for the first time.

The visits to the quarry were also used to recharge the film container and to adjust the sensitivity of the photocell amplifier. The average operating time of the apparatus after such checks was 54 hours. The relatively long intervals between the checks were largely responsible for the discontinuity of the records (fig. 2B). Another set-back has been that the identification of the species in the photographs it not very reliable. The head markings permit a decision only in some instances, as these are only legible if the animal has passed in a suitable position. However, the genera Myotis and Plecotus can easily be distinguished in the pictures. (The only example of the third genus, Eptesicus serotinus, found only twice in the quarry, is missing in the photographs.)

\section{RESULTS}

Separating both genera revealed a conspicuous difference: In fig. 3 all exit flights by bats as far as recorded are arranged according to genus, to hour of the day and to month. In the middle of the winter flights of Plecotus are apparently more frequent than of Myotis species, although Plecotus specimens in the cave make up only a small fraction of the total bat population (fig. 2). The numbers of in and out flights in both genera, computed per 24 hours of operation of the recorder and per bat present in the hibernaculum are given in table I. These are very rough estimates. However, the data illustrate the difference between both genera. The activity recorded in Plecotus is more than two orders of magnitude larger than in Myotis. This agrees with other features which characterize the Long-eared Bat - probably not $P$. austriacus; see Stebbings, this volume - as one of the hardiest species in our caves: it hibernates in the colder cave areas and is present for a short period only in the middle of the winter. Most of the Myotis species retire for a longer period (Daan \& Wichers, 1968).

In Myotis, the activity outside the quarry gradually decreases until a minimum is reached in February and then in spring rises again nearly to the Plecotus level. This peak is presumably due to regular in and out flights before actual migration to the summer colonies commences. About the same seasonal change in activity has been found earlier in intracave movements (Daan, in press). According to these data, movements from hibernating locations in the same quarry have a frequency of the order of 0.05 per day - the equivalent of once every 20 days - in the three predominant Myotis species in December-February. (See also table II.) This is a conservative estimate as some bats return to their original location after flying round in the quarry, and such movements are not counted.

According to table I, outside flights occur with a frequency of the order of 0.005 per bat per day in the same months (which would be the equivalent of once every 200 days for any bat). This is overestimated, as some bats will pass two or three times through the window before actually 
Table I. Average numbers of recorded fiights per 24 hours per bat found in the quarry. (Koelebosgroeve 1968/69).

\begin{tabular}{lllll} 
& \multicolumn{2}{c}{ Myotis species } & \multicolumn{2}{c}{ Plecotus species } \\
direction: & in & out & in & out \\
October & 0.046 & 0.012 & - & - \\
November & 0.018 & 0.012 & - & - \\
December & 0.005 & 0.006 & 0.6 & 1.7 \\
January & 0.006 & 0.007 & 1.2 & 1.2 \\
February & 0 & 0.007 & 2.2 & 2.6 \\
March & 0.006 & 0.020 & - & - \\
April & 0.79 & 1.15 & - & -
\end{tabular}

leaving the quarry. Moreover, the actual population of bats involved in these flights is larger than the numbers observed as some are invisible in crevices, etcetera. Therefore, the conclusion can be drawn that only a very small fraction of the arousals actually lead to flying around outside the quarry. Inferred from this observation, and from the extreme scarcity of insects dormant in the quarry investigated, we may readily conclude that the bats of the genus Myotis under study did not feed during most of the hibernating season.

This conclusion would not necessarily hold for Plecotus spec. Roer (1969) supposes both $P$. auritus and $P$. austriacus to feed regularly during the winter. Also, the Greater Horseshoe Bat (Rhinolophus ferrumequinum) has been found to feed during midwinter flights from its hibernation quarters in the much milder climate of southern England (Ransome, 1968). However, Saint Girons et al. (1969) presented evidence for com- plete fasting from late December to late March in this species in western France.

The outside flights from the hibernaculum take place exclusively between sunset and sunrise (fig. 3). The distribution during the night seems to be fairly homogenous apart from a slight peak just after dusk. From other observations (table II)

Table II. Average relative frequency of spontaneous displacements from locations in two quarries per period of 8 hours (species combined). Observations made during field excursions of the Laboratory of Animal Physiology.

\begin{tabular}{|c|c|}
\hline $\begin{array}{c}\text { "Sibbergroeve" } \\
\text { January 4-10, } 1969\end{array}$ & $\begin{array}{l}\text { "Barakkengro } \\
\text { January 3-9, } 1\end{array}$ \\
\hline $68-83$ & $67-97$ \\
\hline 0.026 & 0.020 \\
\hline 0.008 & 0.008 \\
\hline 0.026 & 0.022 \\
\hline 0.06 & 0.05 \\
\hline
\end{tabular}

made during two series of 8 hour-interval searches in other quarries it can be concluded that movements from locations within the cave take place also in daytime, though at a lower rate than during the night. Apparently, daylight at the entrance deters any tendency to fly out. The peak after sunset is then presumably caused by bats which became active in daytime and waited for dusk behind the entrance. Also, repeatedly trying outside light conditions may add to the total number of flights around sunset.

\section{REFERENCES}

BöHME, Wolfgang \& GÜNTER NATUSChKE, 1967. Untersuchung der Jagdfiugaktivität freilebender Fledermäuse in Wochenstuben mit Hilfe einer doppelseitigen Lichtschranke und einige Ergebnisse an Myotis myotis (Borkhausen, 1797) und Myotis nattereri (Kuhl, 1818). Säugetierk. Mitt., 15 (2) : 129-138.

DAAN, SERGE, in press. Frequency of displacements as a measure of activity in hibernating bats. Proc. 1 intern. Chiropt. Conf., Lynx.

DAAN, S. \& H. J. Wichers, 1968. Habitat selection of bats hibernating in a limestone cave. Z. Säugetierk., 33 (5) : $262-287$.

ENGLÄNDER, H. \& G. LAUfENS, 1968. Aktivitätsuntersuchungen bei Fransenfledermäusen (Myotis nattereri Kuhl, 1818). Experientia, 24: 618 619.

Kristofferson, Rolf \& ANTTI SoIvio, 1967. A comparative long-term study of hibernation in finnish and german hedgehogs in a constant ambient temperature. Ann. Acad. scient. Fenn., A IV $122: 1-23$.
Nyнolm, ERIK S., 1965. Zur Okologie von Myotis mystacinus (Leisl.) und M. daubentonii (Leisl.). Ann. zool. Fenn., 2 : 77-123.

Pohl, HermanN, 1967. Circadian rhythms in hibernation and the influence of light. In : K. C. Fischer et al. (eds.), Proc. 3 intern. Symp. Mammal. Hibern.: 140-151 (Oliver \& Boyd, Edinburgh).

RAnsome, R. D., 1968. The distribution of the Greater horseshoe bat, Rhinolophus ferrumequinum during hibernation, in relation to environmental factors. $J$. Zool. (London), 154 : 77-112.

RoER, H., 1969. Zur Ernährungsbiologie von Plecotus auritus (L.) (Mam. Chiroptera). Bonn. zool. Beitr., 20 (4) : 378-383.

Saint Girons, H., A. Brosset \& M. C. Saint Girons, 1969. Contribution à la connaissance du cycle annuel de la chauve-souris Rhinolophus ferrumequinun (Schreber, 1774). Mammalia, 33 (3) : 357-470. 